\title{
Realistic assessment of slope reliability for effective landslide hazard management
}

\author{
R. W. M. CHEUNG* and W. H. TANG $\dagger$
}

Probabilistic methods have been employed as a practical aid for slope management in respect of the stochastic nature of landsliding. The effect of deterioration on the reliability of slopes of various periods of service, however, has seldom been considered explicitly in the current reliability evaluation. The first part of this paper will present an empirical procedure, using past performance of an extensive set of cut slopes in Hong Kong as an example, to model probabilistically the deteriorating effect on the failure probability with age for a population of slopes. The procedure extends further to predict the failure probability of slopes over different future service periods. Although this probability would serve as an estimate of average slope reliability to assist landslide hazard management by planners, a more accurate sitespecific failure probability would be preferred for individual projects. The second part of this paper will adopt a Bayesian procedure to map the calculated probability of a given slope to a more realistic estimate of failure probability. The procedure enables performance records, the effect of system deterioration and other unaccountedfor factors to be systematically incorporated for the estimation. Finally, a procedure is developed to assess the uncertainty associated with the updated probability, resulting from limited observed performance data available for the probability mapping process.

KEYWORDS: failure; landslides; slopes; statistical analysis; time dependence
Nous employons des méthodes probabilistes comme aide pratique à la gestion des pentes par rapport à la nature stochastique des glissements de terrain. Cependant, l'effet de détérioration sur la fiabilité des pentes sur diverses périodes de service a été rarement pris en compte de manière explicite dans l'évaluation de la fiabilité actuelle. La première partie de cet exposé présente une procédure empirique, utilisant en exemple les performances passées d'un jeu important de pentes tronquées à Hong Kong pour modéliser de manière probabiliste l'effet détériorant sur la probabilité de rupture dans le temps pour une population de pentes. La procédure va jusqu'à prédire la probabilité de rupture de pentes sur diverses périodes de service dans le futur. Cette probabilité pourrait servir pour estimer la fiabilité moyenne des pentes et aider les planificateurs à mieux gérer les risques de glissement mais une probabilité de rupture plus spécifique au site et plus exacte serait préférable pour des projets individuels. La seconde partie de cet exposé adopte une procédure bayésienne pour cartographier la probabilité calculée d'une pente donnée dans une estimation plus réaliste de la probabilité de rupture. La procédure permet d'incorporer de manière systématique les performances, l'effet de la détérioration du système et d'autres facteurs non expliqués pour évaluation. Enfin, nous développons une procédure pour évaluer l'incertitude associée à la probabilité remise à jour et résultant du peu de données de performances observée disponibles pour le processus de mise en carte de la probabilité.

\section{INTRODUCTION}

Natural disaster, by its nature, is always complicated and unpredictable. Landslide is one of the major geo-hazards accompanied by uncertainties that causes hundreds of deaths worldwide every year. For example, rain-induced landslides have caused more than 470 fatalities in Hong Kong since the late 1940s. Many parts of the world have been endeavouring to manage the risk associated with landslide to an acceptable level (Fell, 1994; Morgenstern, 1997). Because of the stochastic nature of this hazard, probabilistic methods are commonly invoked as a practical aid for landslide risk assessment (e.g. Wu et al., 1996; Einstein, 1997). From a macroscopic point of view, a reasonably accurate evaluation of average slope performance is essential for effective resource allocation. For instance, if the severity of landslide can be predicted before the onset of rainstorms, the landslide risk posed to the public will be greatly reduced. While the average reliability can serve as a parameter to manage the

Manuscript received 28 April 2004; revised manuscript accepted 22 October 2004.

Discussion on this paper closes 1 August 2005, for further details see p. ii.

* Civil Engineering and Development Department, Government of the Hong Kong SAR, China.

$\dagger$ Hong Kong University of Science and Technology, Hong Kong SAR, China. territory-wide landslide risk, a more accurate failure probability will be preferred for individual projects, particularly when more information is available for a specific slope under consideration. This helps the design of more costeffective retrofitting and maintenance works. This paper will establish a model whereby a more realistic assessment of slope reliability, both average and site specific, can be obtained for effective landslide hazard management.

GENERAL DESCRIPTION OF SLOPES IN HONG KONG

The geology of Hong Kong has been well documented in the literature (e.g. Ruxton, 1960; Allen \& Stephens, 1971; Fyfe et al., 2000; Sewell et al., 2000). The main rock types are granite and volcanic rocks. The terrain is covered by a thick mantle of decomposed rocks or colluvium. The granite is extensively weathered throughout the territory, with depths of silty, sandy soil of up to $60 \mathrm{~m}$. The volcanic rocks are more resistant to weathering than granite, and the soil mantle is up to about $20 \mathrm{~m}$ thick. The topography is generally steep, with more than $30 \%$ of the terrain steeper than $30^{\circ}$.

Because of the lack of flat areas, developments have been encroaching onto the steep terrain. This has given rise to the formation of more than 55000 registered slope features (i.e. cuts, fills and retaining walls) throughout the territory of Hong Kong. A registered slope feature is a man-made 
feature that satisfies a set of criteria. For example, a cut slope is eligible for registration if it is greater than $3 \mathrm{~m}$ high. Among the population of slopes, more than half were formed before the implementation of geotechnical control in 1977. They are referred to as 'old slopes'. These old slopes were designed and constructed primarily on the basis of judgement and rules of thumb, and most of them are too steep by the current standard (Brand, 1985). Cut slopes are commonly $40-70^{\circ}$, and fill slopes are $30-35^{\circ}$. Because of the lack of geotechnical control, and because most of the slopes are subject to severe deterioration, they are susceptible to failure, particularly during the rainy season, when severe rainstorms are associated with tropical typhoons or low-pressure troughs.

On average, hundreds of rain-induced landslides are reported each year, and most of the failures involve old slopes. Most of the slip surfaces are shallow, and the thickness of scars is usually less than $3 \mathrm{~m}$. Attempts have been made in the past to establish correlation between various parameters, such as slope angle, slope height and soil type, and the likelihood of landslide. Yet none of the studies can reveal a simple relationship between these parameters (Brand, 1984). Because of the large number of old cut slopes (about $70 \%$ of the old slope population), most of the territory-wide landslide risk is attributed to this class of slope (Cheung et al., 2001). This suggests that one can effectively manage the territory-wide landslide risk if the reliability of this slope class can be estimated with reasonable accuracy.

Like many parts of the world, Hong Kong has been trying to reduce the landslide risk to as low a level as is reasonably practicable. A comprehensive slope safety system has been established to manage the territory landslide risk arising from these slopes, in particular the old ones (Chan, 2000). The system consists mainly in upgrading substandard slopes through engineering means, maintaining slopes, land-use planning in respect of landslide risk, public education and landslip warning. As part of the system, a territory-wide automatic rain gauge network has been established since 1984 to study the spatial characteristics of rainfall as well as its correlation with landsliding. Rainfall data are recorded automatically at $5 \mathrm{~min}$ intervals on a $24 \mathrm{~h}$ basis. In the context of this paper, a rainstorm is defined as an event in which a rolling $24 \mathrm{~h}$ rainfall, $i_{24}$, recorded at the Hong Kong Observatory, exceeds $50 \mathrm{~mm}$. This definition is adopted because it includes all of the largest rainstorm events in the reported period. In addition, past studies (e.g. Brand et al., 1984) have indicated that the maximum rolling 24 hour rainfall, $i_{24 \max }$, correlates highly with the occurrence of landslides. It is a good parameter to indicate the likelihood of landslides.

During the period 1984 to 2002 there were 208 rainstorms of this nature, with a maximum of 18 in 1997 and a minimum of 5 in 1999. For ease of studying the reliability of slopes under different rainfall characteristics, the territory has been divided into a grid of 1600 small cells, of which 860 cells fall on land. Each cell has a plan area of $1.5 \mathrm{~km}$ $\times 1.2 \mathrm{~km}$. Whenever a rainstorm occurs, the rainfall data recorded at the rain gauges will be used to interpolate the rainfall intensity at each of the 1600 cells (Yu, 2004). For each of the 208 rainstorms, the geographical characteristics of the rainfall will be represented by the spatial distribution of the maximum rolling $24 \mathrm{~h}$ rainfall, $i_{24 \max }$, among the 1600 cells. Each cell will have its own $i_{24 \max }$. For instance, Fig. 1 illustrates the distribution of $i_{24 \max }$ for the rainstorm that occurred between 1 and 4 July 1997 . The rainfall intensity is divided into three categories: $0-200 \mathrm{~mm} /$ day, $200-400 \mathrm{~mm} /$ day, and $>400 \mathrm{~mm} /$ day. With reference to the same grid of cells and the locations of the slopes, some 20000 old cuts can be distributed to the appropriate cells as indicated in Fig. 2, where the numbers represent the numbers of slopes in the subject cells.

\section{AVERAGE RELIABILITY OF SLOPES}

Knowledge of the average reliability of slopes is essential to landslide risk management over the territory. For example, one may carry out a risk assessment over a large area and express the results in the form of a landslide hazard/risk map (Brabb, 1984).

In addition to analytical studies, the past performance of slopes, particularly when data on individual slopes such as geology, geometry, engineering parameters and underground

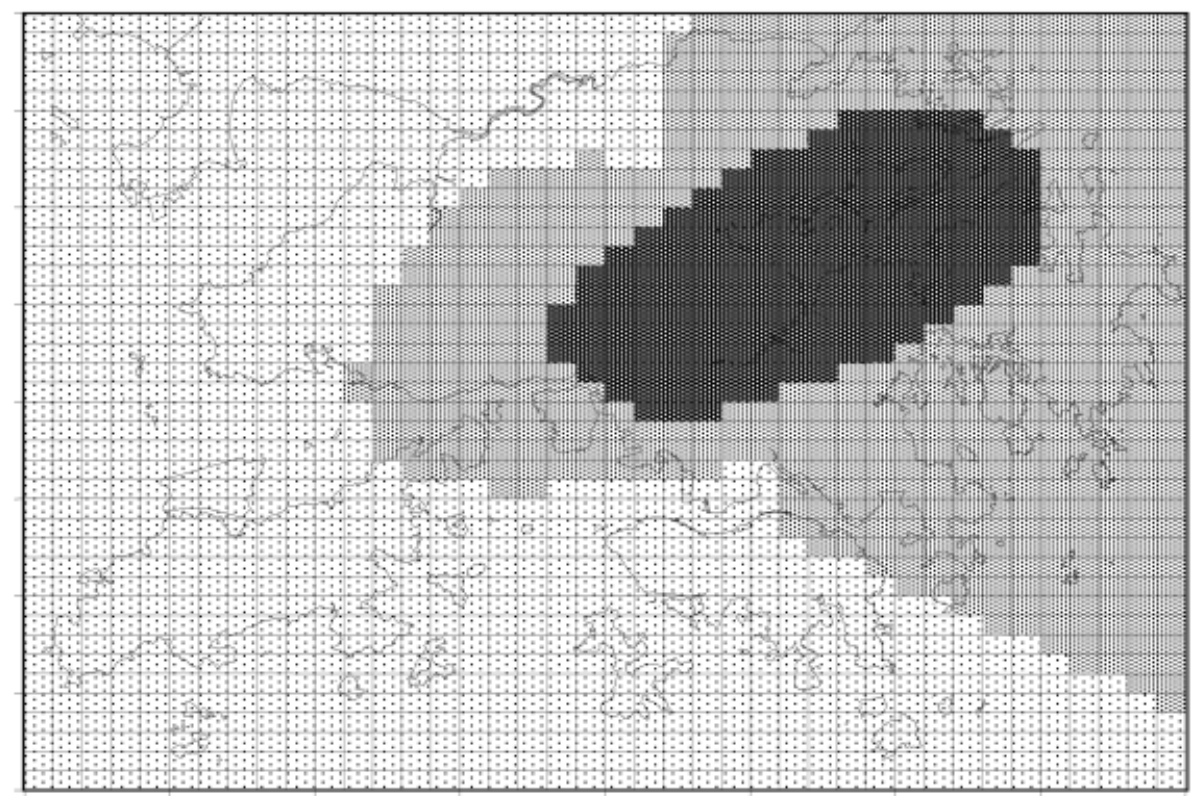

$i_{24 \max }=0-200 \mathrm{~mm} / \mathrm{day}$

$i_{24 \max }=200-400 \mathrm{~mm} / \mathrm{day}$ $i_{24 \max }=>400 \mathrm{~mm} / \mathrm{day}$

Fig. 1. Distribution of maximum rolling $24 \mathrm{~h}$ rainfall, $i_{24 m a x}$, among small cells for rainstorm of 1-4 July 1997 


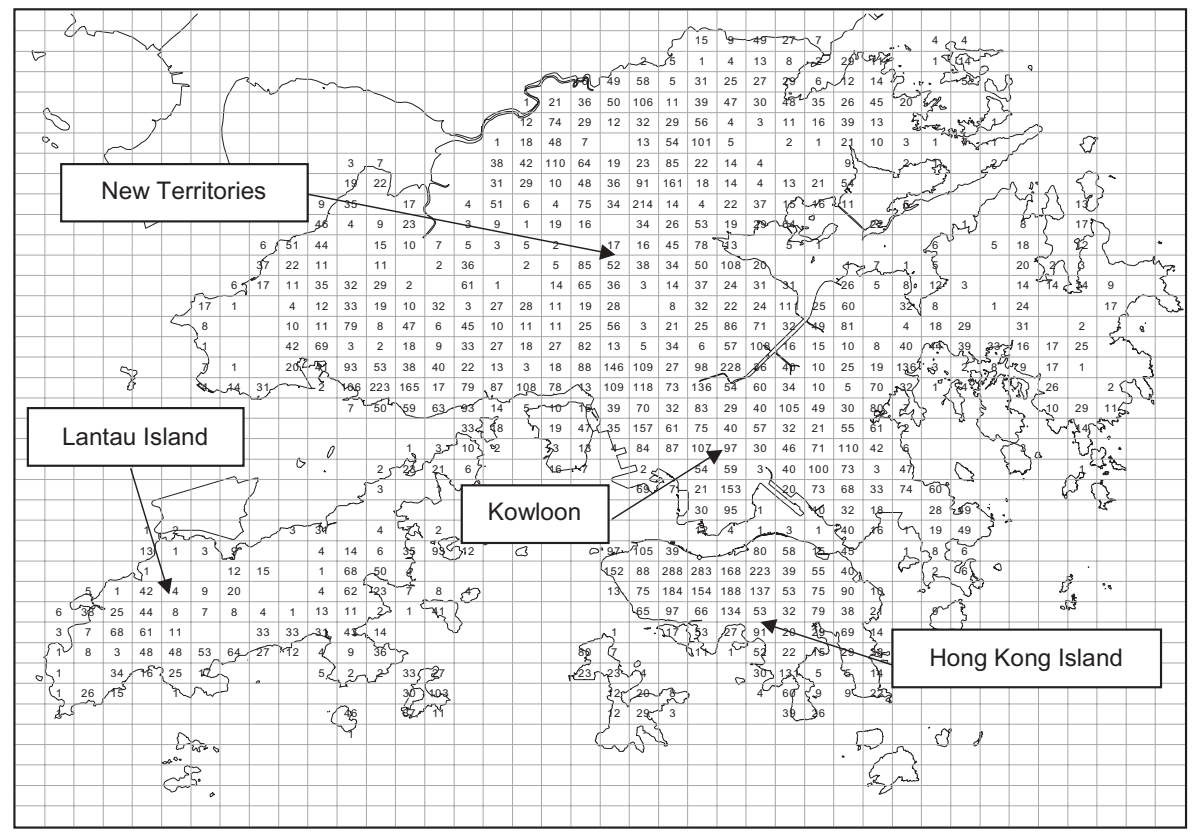

Fig. 2. Spatial distribution of old cuts in the territory

water regime are not available, provides valuable information for evaluating the average reliability of slopes, and hence the effectiveness of the slope safety system. Among the vast amount of information, data on the performance history of the old cut slopes in the period 1984-2002, including the time of formation and the time of first failure, have been retrieved. The youngest and oldest slopes were 7 and 31 years old respectively in 1984 (the beginning of the availability of comprehensive rainfall data). By the end of 2002 (the end of the observation period) these slopes were 26 and 50 years old respectively. More than 1100 landslides were reported over the observation period.

For each of the rainstorms, relevant cuts and landslides in response to the three rainfall intensity categories from each of the small cells have been identified and grouped. The number of slopes hit by rainstorms (called 'rainstorm hits' hereafter) is then grouped according to slope age and rainfall intensity. The grouping of rainstorm hits for the 208 rainstorms under different categories of rainfall intensity and slope ages is shown in Fig. 3. Similar grouping has been carried out for the failures, as shown in Fig. 4. This records the first time that a slope failed. Once a slope has failed, it will be excluded from the sample of slopes in the next rainstorm event. The reason for this is that slope repair or retrofitting works will be carried out after each failure, and the characteristics of these repaired slopes will be different from those remaining in the sample.

Based on the set of data in Figs 3 and 4, the conditional rate of failure for $t$-year-old slopes subjected to a given rainfall intensity can be estimated as follows:

$$
\hat{h}\left(t, i_{24 \max }\right)=\frac{\begin{array}{l}
\text { Number of } t \text {-year-old slopes that failed } \\
\text { at a rain storm of intensity } i_{24 \max }
\end{array}}{\begin{array}{l}
\text { Number of rain storm hits of intensity } \\
i_{24 \max } \text { on } t \text {-year-old slopes }
\end{array}}
$$

The conditional rate of failure given by equation (1) is equivalent to the hazard function that is commonly used in reliability analysis to denote the instantaneous rate of failure for a currently operating system. The estimated hazard function for slopes subjected to a rainfall intensity of 200$400 \mathrm{~mm} /$ day is shown in Fig. 5. The failure probability is not a constant value as commonly assumed. Instead, it appears that the failure probability increases gradually with slope age. Similar trends have been revealed for slopes under rainstorms of the other two intensity categories. One possible reason for this increasing trend is ageing effect. In the context of this paper, ageing effect refers to deterioration in the form of degradation of surface cover, blockage or damage of surface and subsurface drainage systems, and reduction of soil strength due to weathering of slope-forming materials or temporal fluctuation of pore pressure. Apart from the increasing trend, there is a scatter of failure probability about the trend. This scatter mainly reflects the stochastic nature of the reliability of individual slopes and the amount of data available for each estimate.

From the perspective of engineering planning, it will be more convenient if the reliability of these deteriorating slopes can be described by a probabilistic model. The Weibull distribution can be applied to a wide range of problems, particularly in modelling the relative likelihood of failure time of a deteriorating engineering system (Weibull, 1951). The hazard function $h(t)$ for a Weibull distributed time to failure $t$ is expressed in the following form:

$$
h(t)=\lambda \gamma(\lambda t)^{\gamma-1}
$$

where $\gamma$ is the shape parameter, which governs the rate of change of the hazard function, and $\lambda$ is the scale parameter, which dictates the spread of the distribution.

On the basis of equation (2), hazard plots of the slope performance data with respect to the three categories of rainfall intensity can be constructed (Nelson, 1972; Cheung, 2004). Fig. 6 shows the hazard plot corresponding to $i_{24 \max }$ $=200-400 \mathrm{~mm} /$ day in log-log scale. Note that cumulative probability is used in the plot to smooth out any statistical scatter so that the trend can become more apparent. The plot indicates that the observed time to failure fits a bilinear Weibull distribution well if the data on the observation period are divided into two groups: 7-16 years and 17-50 years. The two distributions were not rejected by the goodness-of-fit test proposed by Hollander \& Proschan (1979) at $5 \%$ significance level. The shape parameter $\gamma$ and the scale parameter $\lambda$ of the two Weibull distributions are estimated 


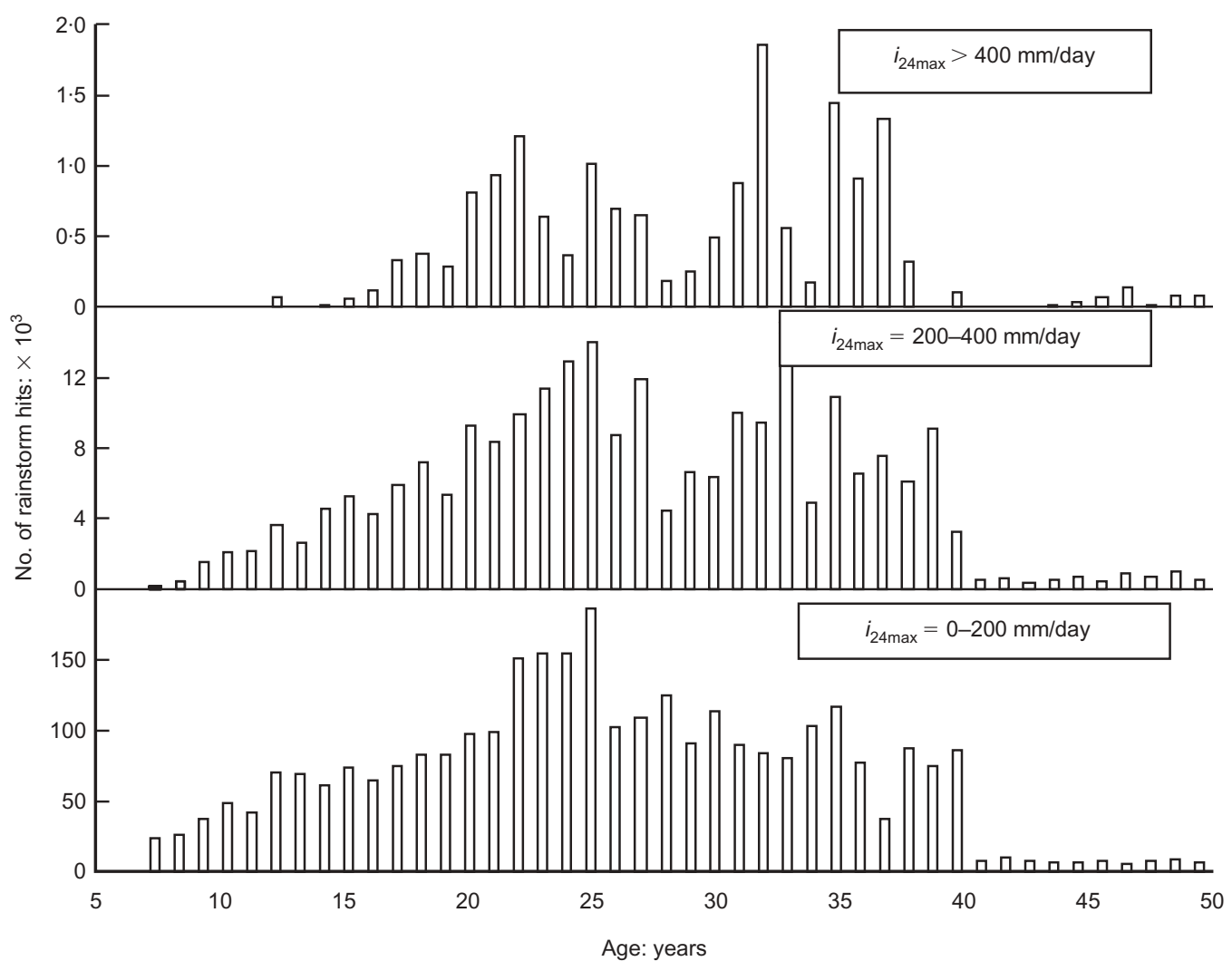

Fig. 3. Number of rainstorm hits on old cut slopes in period 1984-2002

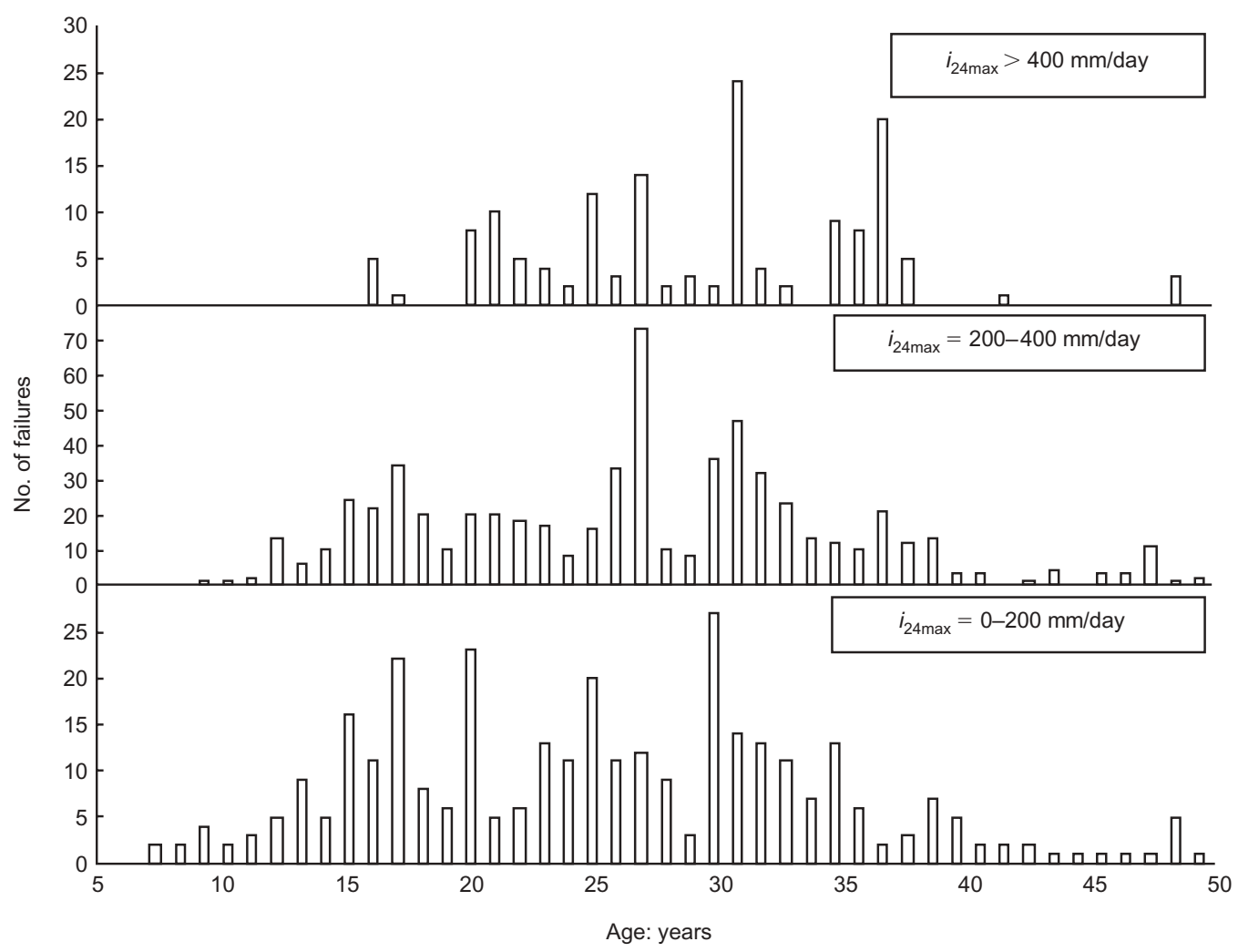

Fig. 4. Number of old cut failures in period 1984-2002

to be $\hat{\gamma}_{1}=6.54$ and $\hat{\lambda}_{1}=0.0359$, and $\hat{\gamma}_{2}=1.48$ and $\hat{\lambda}_{2}=$ $0 \cdot 0048$, respectively.

As indicated in equation (2), the hazard function increases monotonically if the shape parameter $\gamma$ is greater than unity. Given $\hat{\gamma}_{1}=6.54$ and $\hat{\gamma}_{2}=1.48$ in this case, one would expect the conditional annual failure probability to increase with slope age. This confirms the observed trend from Fig. 5. However, a lower value of shape parameter, and hence a lower rate of increase in probability, is obtained after the first 16-year service, suggesting that the performance of slopes beyond this age has been improved. Indeed, similar change in the shape parameter after the first 16-year service 


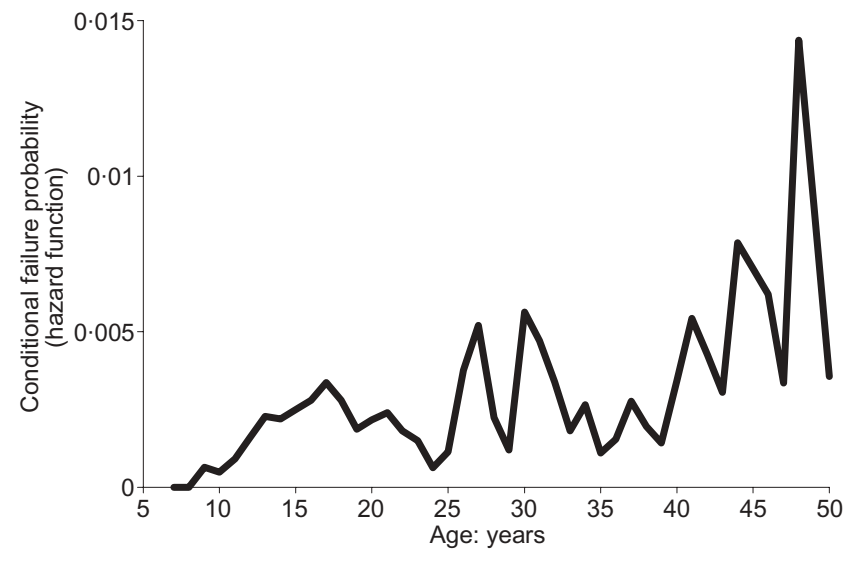

Fig. 5. Temporal variation of conditional failure probability of old cuts under a rainstorm of $200-400 \mathrm{~mm} /$ day intensity

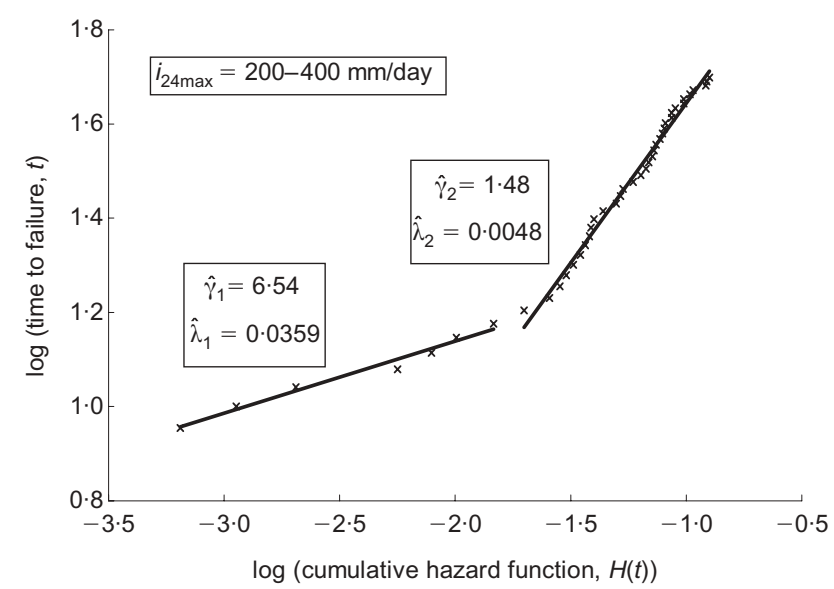

Fig. 6. Hazard plotting for time of failure

has also been obtained for slopes in the rainstorm category $i_{24 \max }=0-200 \mathrm{~mm} /$ day. This apparent change in the shape parameter, however, is not obvious for slopes in the rainstorm category $i_{24 \max }>400 \mathrm{~mm} /$ day.

The three hazard functions on log scale under different rainfall intensities are shown in Fig. 7. Note that the changes in shape parameters for the performance of slopes under rainstorm categories $i_{24 \max }=0-200$ and $200-400 \mathrm{~mm} /$ day are manifested by the discontinuities in the curves. One possible reason for a lower rate of increase in the probability of failure after the first 16 years' service could be the proofing-test effect. Strictly speaking, the hazard functions presented in Fig. 7 represent only the average reliability of slopes. Although the slopes are of a similar class, they have different reliabilities because of their different characteristics (such as different geometrical configurations and applied loads) and the level of uncertainties implicit in individual slopes. Thus those that survived after age 16 may have strength characteristics different from those that have already failed. The weaker slopes may have already failed in the early service period. This phenomenon is referred to as the proofing-test effect.

Another possibility accounting for this lower rate of increase in failure probability could be a retardation of deterioration. After a reasonably long period of service, for example in this case probably about 16 years, the slope owners may have become aware of the poor conditions of their slopes and have carried out maintenance works that counterbalanced the effect of deterioration. Indeed, a pub-

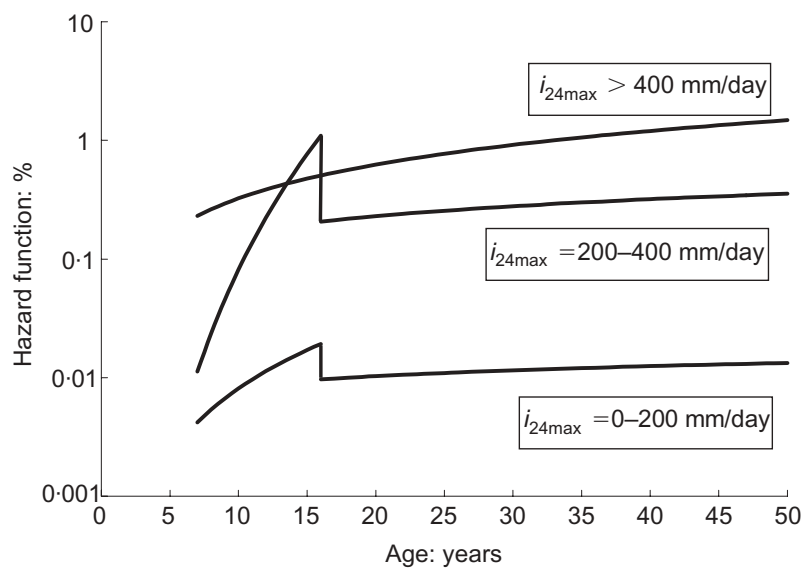

Fig. 7. Variation of hazard function under different categories of rainfall intensity

licity campaign on slope maintenance was initiated in 1992 to increase public awareness of the importance of slope maintenance and the owners' liability to keep their slopes in good condition. Since the youngest slopes in the population were 16 years old in 1992, it is likely that the performance of those slopes younger than this age had not been affected by this publicity campaign. This means that the performance data, as indicated in Figs 3 and 4 for slopes older than 16, may include some effect of maintenance works. As mentioned earlier, it is apparent that no changes in the Weibull parameters (i.e. the shape and scale parameters) for slopes in the rainstorm category $i_{24 \max }>400 \mathrm{~mm} /$ day have been observed. This suggests that the effect of slope maintenance alone, if it exists, may not be sufficient to improve the performance of slopes, particularly under rainstorms of severe intensity. In essence, by studying the changes of hazard function, one can determine the overall performance of the slopes in respect of the effectiveness of action that has been taken.

Apart from gauging and monitoring the average reliability of slopes, the ability to predict the number of landslides under a given rainfall intensity is important in enhancing effective risk management. In the previous section, a model that relates the probability of cut failure of different ages to rainstorms of different intensities has been developed. It would be of interest to verify whether this correlation model is suitable for serving as a landslide prediction tool. In 2003 there were six rainstorms, and the spatial distribution of the maximum rolling $24 \mathrm{~h}$ intensity $i_{24 \max }$ of each rainstorm among the small cells has been determined. Based on the spatial distribution of the rainfall intensity and the location of cut slopes, one can use the probabilistic model and equation (3) to predict the number of cut failures, $N_{\mathrm{f}}$, for each rainstorm. The prediction and the actual values are summarised in Table 1;

$$
N_{\mathrm{f}}=\sum_{\substack{\text { all } \\ \text { cells }}} \sum_{\substack{\text { all } \\ i_{24 \max }}} \sum_{\substack{\text { all } \\ \text { ages }}} h\left(t, i_{24 \max }\right) n\left(t, i_{24 \max }\right)
$$

where $h\left(t, i_{24 \max }\right)$ is the hazard function corresponding to $t$ year-old cuts under rainfall intensity $i_{24 \max }$, and $n\left(t, i_{24 \max }\right)$ is the number of rainstorm hits of intensity $i_{24 \max }$ on $t$-yearold cuts.

It is evident from Table 1 that the prediction can be made with reasonable accuracy. When the rainfall intensity is high, as in the rainstorms that occurred in May and June, it seems that the probabilistic model will overestimate the number of failures. If the rainfall intensity is low, neither a trend of overestimation nor underestimation can be observed. Nonetheless, the model appears promising as a quick landslide- 
predicting tool before the onset of a rainstorm. More data would be collected in the future in order to confirm the reliability of the model.

The hazard function shown in Fig. 7 represents the contribution of different categories of rainstorm to the conditional probability of failure. If the chances of rainstorms of different intensities occurring are taken into account, one can determine the reliability of slopes of various service periods by virtue of the total probability theorem. On this basis, the reliability of a slope over any given future period can also be determined by probability theory (Cheung, 2004). Instead of predicting the performance of the old slopes when they were first constructed, it will be more useful if some light can be shed on the risk and remaining life of those old slopes that have not failed. Two cases are given in Fig. 8. They are more relevant to planners in assessing the risk arising from the remaining life of the old slopes. For example, the 20 -year-old cut slopes will have a probability of failure of $4 \%$ over the next 20 years' service. This probability will increase to $5 \%$ when they are 40 years old. Thus, if a $95 \%$ reliability level for the next 20 years is desired, maintenance or retrofitting of slopes older than 40 years will be required.

\section{RELIABILITY OF A SPECIFIC SLOPE}

The reliability of cut slopes as presented earlier represents the average performance of slopes of similar characteristics. This information is very useful in serving as a practical aid for territory-wide landslide risk management, and perhaps provides an initial estimate of the slope reliability. However, it may have little or even no meaning for individual slopes in isolation, particularly when adequate data such as geology, geometry, engineering parameters and underground water regime are available for the slope under consideration, thus affording a site-specific reliability evaluation. Numerous applications of reliability method on a specific slope can be found in the literature (e.g. Vanmarcke, 1977; Li \& Lumb, 1987; Christian et al., 1994; El-Ramly et al., 2002). Although one can follow the procedures of a formal reliability analysis (e.g. Ang \& Tang, 1984) to evaluate the reliability of a specific slope, a limitation of the conventional reliability model has been that the failure probability was inevitably determined on the basis of certain assumed deterministic and probabilistic models. For example, one may establish the performance of a slope based on limit equilibrium, adopt an undrained analysis, and use a first-order reliability method to determine the reliability index $\beta$ of a slope, where $\beta$ indicates the safety margin of the slope in the presence of uncertainties (e.g. Ang \& Tang, 1984). Yet this model is no more than an abstraction of the state of nature, and is subject to unavoidable model error. No matter how sophisticated the model is, it is unlikely, if not impossible, to capture the state of nature entirely. The probabilities obtained in a reliability analysis are therefore at best 'calculated' or 'notional' probabilities. They may not denote those probabilities governing the actual reliability of the slopes.

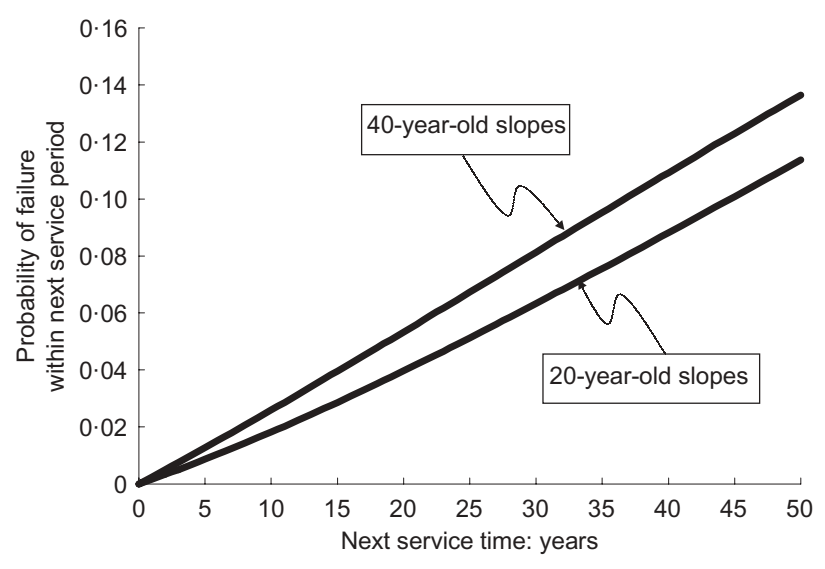

Fig. 8. Probability of failure for old cuts of different ages

Observed performances can again help to calibrate this calculated probability for the model error that may have been accrued. Unlike tossing a coin, a repeatable performance record of a slope cannot be obtained without changing its characteristics when failure occurs. Although the performances of many other old cut slopes are available, they will have varying calculated probabilities because of the different geometries, site characteristics and levels of uncertainty implicit in individual slopes. Hence they will not normally form a single population for calibration purposes. Nevertheless, it will be desirable if a procedure can be developed such that performance records of slopes with different calculated reliabilities can be combined for the calibration. The deterioration effect assessed for the average reliability can be incorporated at the same time. For this purpose, the actual failure probability associated with a slope whose calculated reliability index is $\beta$-that is, $P(F \mid \beta)$ - has been developed by a group of researchers, including the authors, for updating the estimates of probability of liquefaction and slope failure with field performances (Juang et al., 1999; Cheung \& Tang, 2000; Juang et al., 2001). For a new slope of a similar class, if the same procedure is used to determine its reliability index, $\beta$, the updated probability of failure can be determined as

$$
P(F \mid \beta)=\frac{f_{\mathrm{F}}(\beta) P(F)}{f_{\mathrm{F}}(\beta) P(F)+f_{\mathrm{NF}}(\beta) P(N F)}
$$

where $P(F \mid \beta)$ is the probability of slope failure for a given value of $\beta, P(F)$ is the prior probability of slope failure, $P(N F)$ is the prior probability of no slope failure, $f_{\mathrm{F}}(\beta)$ is the probability density function of reliability index at a value of $\beta$ for slopes with past failure records, and $f_{\mathrm{NF}}(\beta)$ is the probability density function of reliability index at a value of $\beta$ for slopes without past failure records.

\section{Prior probability of failure}

The prior probabilities represent our knowledge of the slope before a reliability analysis is performed. The prob-

Table 1. Predicted and actual number of cut failures in 2003

\begin{tabular}{|c|c|c|c|c|c|}
\hline \multirow[t]{2}{*}{ Rainstorm period } & \multicolumn{3}{|c|}{ No. of small cells on land under rainfall intensity } & \multirow{2}{*}{$\begin{array}{l}\text { Actual no. of } \\
\text { failures }\end{array}$} & \multirow{2}{*}{$\begin{array}{l}\text { Predicted no. of } \\
\text { failures }\end{array}$} \\
\hline & $0-200 \mathrm{~mm} /$ day & $200-400 \mathrm{~mm} /$ day & $>400 \mathrm{~mm} /$ day & & \\
\hline 7-10 April & 860 & 0 & 0 & 1 & 2 \\
\hline 4-7 May & 230 & 601 & 29 & 38 & 43 \\
\hline 9-16 June & 590 & 270 & 0 & 18 & 23 \\
\hline 21-26 August & 860 & 0 & 0 & 4 & 3 \\
\hline 1-4 September & 860 & 0 & 0 & 3 & 2 \\
\hline 14-17 September & 826 & 34 & 0 & 2 & 5 \\
\hline
\end{tabular}


abilities may be assessed based on judgement and/or more objectively through analysis of the failure statistics of a similar class of slopes. In the present case, those probabilities as estimated for the average slope reliability in the first part of the paper can provide suitable prior probabilities. The advantage of using the average slope reliability is that it is determined from a large amount of performance data, and therefore the estimate can be more representative. Moreover, through this prior probability, the effect of deterioration, which it is difficult to incorporate in a conventional reliability model, can be incorporated for a slope of given age.

\section{Probability density function of reliability index}

The probability density function of the reliability index can be established empirically from performing site-specific reliability analysis with a prescribed procedure for a substantial number of slopes with and without failure history. A total of 145 cut slopes (55 with failure records and 90 without) have been selected for site-specific reliability evaluation for the next 50-year service. The performance of a slope is formulated on the basis of the generalised method of slices, and the variability of pertinent parameters is established by conducting statistical analysis of laboratory or field test data. For example, to obtain statistical parameters of shear strength of different soil types for individual slopes, the regional strength parameters, which are derived from more than 1000 triaxial test results, have been combined with those parameters determined from site-specific exploration programmes by probability theory (Cheung, 2004). Landslides in Hong Kong are usually shallow in nature, and the effective stress acting on the slip surface is low, with a typical value of about $30-200 \mathrm{kPa}$ (Brand, 1985). In establishing the regional soil strength parameters, the results of those tests that were conducted outside this stress range have been discarded. The regional statistical strength parameters of different soil types are shown in Table 2. The combination of regional and site-specific strength parameters is necessary because the so-called site-specific parameters are usually obtained from a limited-scale ground exploration programme; by including the regional information more representative parameters for individual slopes can be obtained.

To account for the spatial correlation of soil strength parameters, one can follow the procedure proposed by Tang (1984) to estimate the spatial average strength parameters. In this case the potential failure mass is divided into a number of slices, and each slice has a base length of the order of the scale of fluctuation, $\delta$, where $\delta$ is the extent to which a soil property shows strong correlation. Ideally, the scale of fluctuation should be determined on a site-specific basis through a well-planned ground exploration programme. Yet, owing to the limited resources and time constraints, soil data are usually too limited for meaningful statistical analysis. Therefore the probable range of $\delta$ reported in the literature for a similar soil type (e.g. Keaveny et al., 1989; Soulie et al., 1990; DeGroot \& Baecher, 1993; Lacasse \& Nadim, 1996) has been used as a first-order approximation. Soil strength parameters for different slices are assumed to be uncorrelated.

The reliability index is then determined using a first-order reliability method (Low \& Tang, 1997; Cheung, 2004). The ranges of the calculated reliability index for the non-failed and failed groups are denoted by the rows of dots and crosses respectively in Fig. 9. Apparently, the spread represents the inherent distribution of reliability levels among the group of slopes as well as the resolution of the reliability model in differentiating slopes of different reliability levels. The probability distributions of $\beta$ for the group of failed slopes and that for the group of non-failed slopes are then inferred statistically. They were fitted by normal models, and were not rejected according to the Kolmogorov-Smirnov goodness-of-fit test at 5\% significance level. The respective probability models are also indicated in Fig. 9. In principle, the density function of the failed group should decrease monotonically with $\beta$. However, in reality very few slopes are associated with a very low $\beta$ because they would not have existed in the first place: hence the density function will not begin with very low values of $\beta$. Similarly, the density function of the non-failed group should increase monotonically with $\beta$. However, economic reasons have prevented slopes from being too conservative: hence slopes with exceptionally high values of $\beta$ are expected to be few or non-existent, thus preventing the density function curve from increasing.

\section{Updated reliability of a slope}

Based on the prior probability given by Fig. 8 and the probability density functions of $\beta$ in Fig. 9, the reliability estimate associated with a calculated $\beta$ over the next 50 -year service for slopes of different ages can be updated as in Fig. 10. First, the updated failure probability is substantially lower than the corresponding notional probability: that is, the calculated reliability is conservative for these old cut slopes in Hong Kong. One may notice from Fig. 9 that the

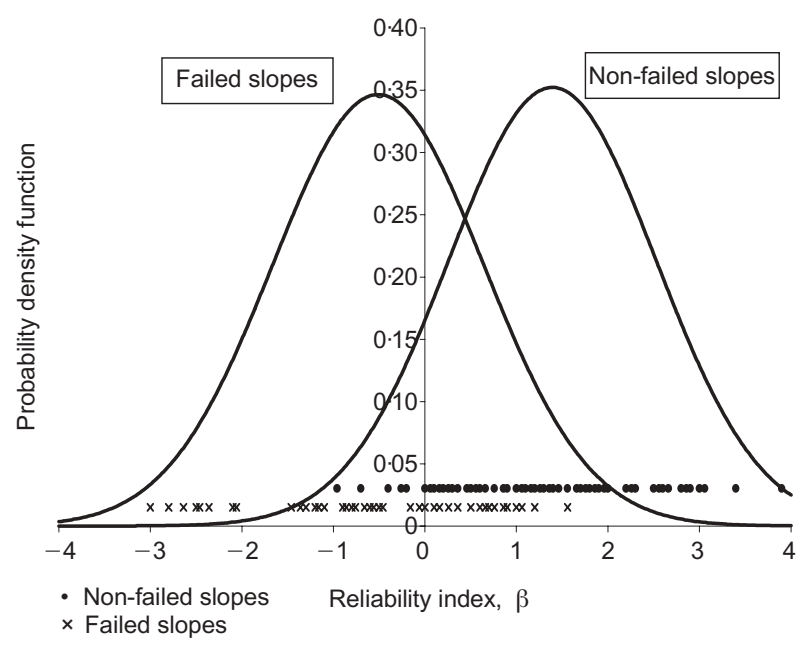

Fig. 9. Distribution of reliability index, $\beta$, for failed and nonfailed slopes

Table 2. Regional statistical strength parameters for different soil types

\begin{tabular}{|c|c|c|c|c|}
\hline \multirow[t]{2}{*}{ Soil type } & \multicolumn{2}{|c|}{ Effective cohesion } & \multicolumn{2}{|c|}{ Angle of internal friction } \\
\hline & Mean: $\mathrm{kPa}$ & $\begin{array}{c}\text { Standard deviation: } \\
\mathrm{kPa}\end{array}$ & Mean: degrees & $\begin{array}{c}\text { Standard deviation: } \\
\text { degrees }\end{array}$ \\
\hline $\begin{array}{l}\text { Completely decomposed granite } \\
\text { Completely decomposed volcanic rocks } \\
\text { Colluvium }\end{array}$ & $\begin{array}{l}3 \cdot 9 \\
5 \cdot 1 \\
5 \cdot 5\end{array}$ & $\begin{array}{l}4 \cdot 4 \\
5 \cdot 2 \\
4 \cdot 7\end{array}$ & $\begin{array}{l}39 \cdot 8 \\
39 \cdot 9 \\
35 \cdot 9\end{array}$ & $\begin{array}{l}4 \cdot 9 \\
5 \cdot 5 \\
5 \cdot 4\end{array}$ \\
\hline
\end{tabular}


two density functions of reliability indices intersect, i.e. $f_{\mathrm{F}}(\beta)=f_{\mathrm{NF}}(\beta)$, when the calculated reliability index is equal to about $0 \cdot 5$. This implies that the updated failure probability will be equal to that estimated for the prior probability (see equation (4)). At this reliability level, the information given by conducting site-specific reliability evaluation may not be better than not doing so; therefore the improvement of the prior probability will be limited. In fact, one would expect the level of reliability of a slope associated with a reliability index of 0.5 to be similar to the average reliability of the slopes.

Fig. 10 also suggests that, for a given reliability index, $\beta$, the probability of failure increases as the age of the slope increases. For example, the probability of failure for a 20 year-old slope of $\beta=0$ over the next 50-year service will increase from $20 \%$ to about $25 \%$ when it is 40 years old. This increase in probability is attributed primarily to the prior probabilities associated with slopes of different ages. However, this ageing effect is clearly small, and it becomes negligible either when $\beta$ is large, say more than 1 , or when $\beta$ is very negative, say less than -3 . Thus, for a slope with high value of $\beta$, it is at such a high safety level that any deterioration effect in the expected service period can be neglected. Similarly, for a slope with extremely low $\beta$, it is so weak that it will fail in the first place. From a design point of view, if the target reliability index is large enough, say more than 2, it may not be necessary to consider the effect of deterioration explicitly, even though the cut slope is old. Moreover, the prior probabilities apparently may not play a significant role in calibrating the calculated probability for a specific site.

\section{Uncertainty of updated probability of failure}

Although observed field performances have been utilised to update the reliability model, the updated probability of failure is only an estimate of the real probability because it is evaluated based on a particular set of slopes. It is inevitable that statistical uncertainty will be introduced. Equation (4) suggests that the updated probability of failure is a function of the two probability density functions $f_{\mathrm{F}}(\beta)$ and $f_{\mathrm{NF}}(\beta)$, and the prior probabilities $P(F)$ and $P(N F)$. It is envisaged that the amount of data available in inferring each of these items will induce uncertainty in the updated probability of failure. Since statistical uncertainties can exist in each of these items, $\mathrm{P}(F \mid \beta)$ can be modelled as a random function. Its overall uncertainty is ascribed to the statistical

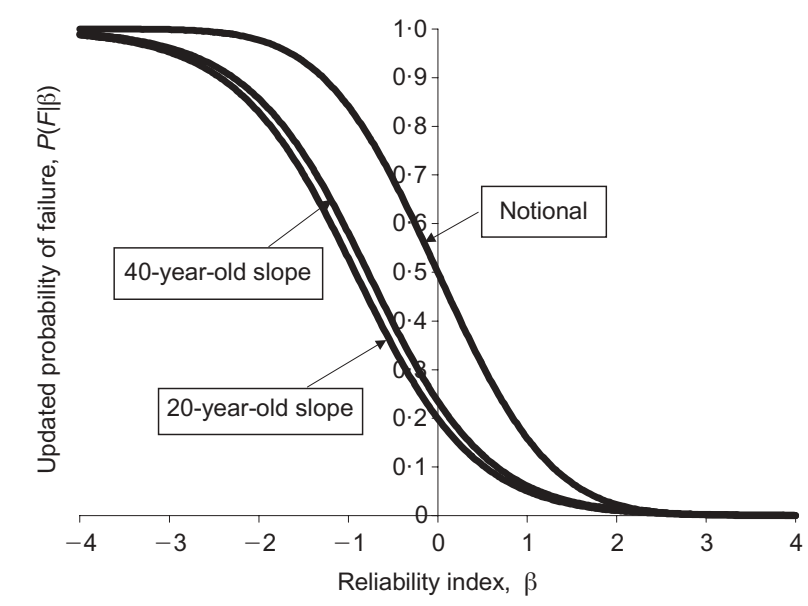

Fig. 10. Updated probability of failure of old cut slopes of different ages for given reliability index $\beta$ over next 50-year service uncertainty in each of these items. The uncertainty in the parameters defining the probability density functions will be affected by the number of performance records used for the updating process. For convenience of practical application, a two-parameter normal distribution has been used to model the probability density functions of $\beta$. The variability of $\beta$ and the uncertainty of a probability density function can then be conveniently characterised by the first two moments of the parameters mean and variance, namely $\mu_{\beta \mathrm{F}}, \sigma_{\beta \mathrm{F}}$ and $\mu_{\beta \mathrm{NF}}, \sigma_{\beta \mathrm{NF}}$ respectively, for the failed and non-failed groups of slopes. Similarly, a two-parameter Weibull distribution has been used to model the prior probabilities with the effects of age and service time of the slopes. The variability of the prior probabilities can be characterised by the uncertainty attributed to shape parameter $\gamma$ and scale parameter $\lambda$. By applying the first-order uncertainty analysis (e.g. Ang \& Tang, 1984), the mean updated probability is obtained by substituting the mean values of $\mu_{\beta \mathrm{F}}, \sigma_{\beta \mathrm{F}}, \mu_{\beta \mathrm{NF}}, \sigma_{\beta \mathrm{NF}}, P(F)$ and $P(N F)$ into equation (4). The variance of the updated probability at a given reliability index $\beta$ is approximately given by

$$
\begin{aligned}
& \operatorname{Var}[P(F \mid \beta)]=\left[\frac{\partial P(F \mid \beta)}{\partial \mu_{\beta \mathrm{F}}}\right]_{\mu}^{2} \operatorname{Var}\left[\mu_{\beta \mathrm{F}}\right]+\left[\frac{\partial P(F \mid \beta)}{\partial \sigma_{\beta \mathrm{F}}}\right]_{\mu}^{2} \\
& \times \operatorname{Var}\left[\sigma_{\beta \mathrm{F}}\right]+\left[\frac{\partial P(F \mid \beta)}{\partial \mu_{\beta \mathrm{NF}}}\right]_{\mu}^{2} \operatorname{Var}\left[\mu_{\beta \mathrm{NF}}\right]+\left[\frac{\partial P(F \mid \beta)}{\partial \sigma_{\beta \mathrm{NF}}}\right]_{\mu}^{2} \\
& \times \operatorname{Var}\left[\sigma_{\beta \mathrm{NF}}\right]+\left[\frac{\partial P(F \mid \beta)}{\partial P(\lambda)}\right]_{\mu}^{2} \operatorname{Var}[\lambda]+\left[\frac{\partial P(F \mid \beta)}{\partial P(\gamma)}\right]_{\mu}^{2} \operatorname{Var}[\gamma]
\end{aligned}
$$

where $\operatorname{Var}[\bullet]$ is the variance of $\bullet$, and $[\bullet]_{\mu}$ is the sensitivity coefficient with $\bullet$ evaluated at mean values.

In equation (5), the parameters $\mu_{\beta \mathrm{F}}, \sigma_{\beta \mathrm{F}}, \mu_{\beta \mathrm{NF}}, \sigma_{\beta \mathrm{NF}}, \gamma$ and $\lambda$ have been assumed to be uncorrelated. This assumption is reasonable because the parameter means (i.e. $\mu_{\beta \mathrm{F}}$ and $\left.\mu_{\beta \mathrm{NF}}\right)$ reflect the average reliability of the slopes, whereas the parameter variances $\left(\sigma_{\beta \mathrm{F}}\right.$ and $\left.\sigma_{\beta \mathrm{NF}}\right)$ indicate the variability of reliability levels among the slopes. They are not expected to be related. Similarly, the shape parameter $\gamma$ governs the rate of change of failure time, whereas the scale parameter $\lambda$ governs the spread of time to failure. As mentioned earlier, a suitable probability density function can be selected by plotting a set of observed values on hazard paper or probability paper and examining its goodness of fit. The uncertainty of the selected distribution can be then assessed by linear regression analysis. Since the parameters governing the selected distribution are usually estimated from the gradient and the intercept of the regression line, the uncertainty of a two-parameter distribution, such as the Weibull distribution or normal distribution, can then be determined from statistical analysis of the uncertainties attributed to the intercept and gradient of the regression line in a hazard or probability plotting. For more details readers are referred to Cheung (2004). By combining the components of uncertainty ascribed to the density functions of the prior and site-specific probabilities, the overall statistical uncertainty of the updated probability can be determined by equation (5). Two cases for slopes that are 20 years old and 40 years old, associated with positive reliability indices $\beta$, are shown in Fig. 11.

The uncertainty given in Fig. 11 is attributed mainly to the components arising from the density functions of the site-specific probabilities. Instead of using site-specific reliability results, one may wonder whether the uncertainty of the probability estimate can be greatly reduced based solely 
on prior probabilities. It should be noted, however, that the prior probability estimate applies for the average probability. For a specific slope, its uncertainty will be substantially higher. For the values of $\beta$ of common interest, the updated probability of failure can be estimated within a reasonable range. For example, for a calculated reliability index of 2 , the updated probability of a 40 -year-old slope over the next 50 -year service is estimated to be $1 \%$, and the 2-sigma band will be about $\pm 0.4 \%$. In other words, there is a probability of more than $95 \%$ that the updated probability will fall within a range of $0 \cdot 6-1 \cdot 4 \%$.

\section{CONCLUSIONS}

The proposed reliability model has been developed for assessing the average and site-specific reliability of old cut slopes. Field performances of slopes have been systematically integrated into the conventional reliability model such that those factors that are difficult to be accounted for, such as ageing effect and model error, can be incorporated to give a more realistic reliability estimate of a slope or a class of slopes. Based on the proposed model, one can estimate the number of slope failures over the territory of Hong Kong more accurately according to the rainfall forecast. This serves as valuable information for the landslide hazard warning system and the identification of those areas with high density of predicted landslides for subsequent follow-up action. The results can also be used to gauge the performance of the slope safety system, thus enhancing the effectiveness of the landslide risk management. In the event that the reliability of a particular slope is of interest, one can use the conventional reliability model to make a first estimate such that the site-specific information, such as slope geometry, geological profile, soil strength parameters, spatial variability of soil properties, and underground water regime, can be incorporated. The probability is then updated with field performance data through the proposed procedure. By integrating with the performance data, or other sources of relevant information, the discrepancy between the calculated and actual probabilities can be minimised.

\section{ACKNOWLEDGEMENTS}

The authors would like to acknowledge the support of the Research Grant Council of Hong Kong through grants No. HKUST6252/00E and HKUST6294/04E. This paper is published with the permission of the Head of the Geotechnical Engineering Office and the Director of Civil Engineering

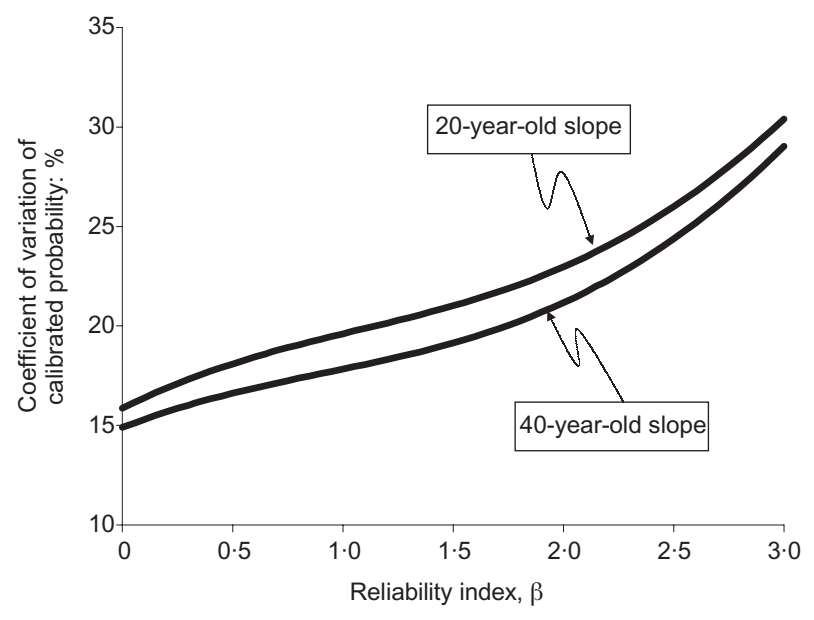

Fig. 11. Statistical uncertainty of updated probability of failure for next 50-year service period and Development, the Government of the Hong Kong Special Administrative Region.

\section{REFERENCES}

Allen, P. M. \& Stephens, E. A. (1971). Report on the Geological Survey of Hong Kong. Hong Kong Government Press.

Ang, A. H.-S. and Tang, W. H. (1984). Probability concepts in engineering planning and design, Vol. II: Decision, risk, and reliability. New York: John Wiley \& Sons.

Brabb, E. E. (1984). Innovative approaches to landslide hazard and risk mapping. Proc. 4th Int. Symp. on Landslides, Toronto 1, 307-323.

Brand, E. W. (1984). Landslides in Southeast Asia: a state-of-the-art report. Proc. 4th Int. Symp. on Landslides, Toronto 1, 17-59.

Brand, E. W. (1985). Predicting the performance of residual soil slopes. Proc. 11th Int. Conf. Soil Mech. Found. Engng, San Francisco 5, 2541-2578.

Brand, E. W., Premchitt, J. \& Phillipson, H. B. (1984). Relationship between rainfall and landslides in Hong Kong. Proc. 4th Int. Symp. on Landslides, Toronto 1, 377-384.

Chan, R. K. S. (2000). Hong Kong slope safety management system (Keynote paper). Proceeedings of a symposium on slope hazards and their prevention, Hong Kong, pp. 1-16.

Cheung, W. M. (2004). Methodology for updating cut slope reliability based on observed performance. $\mathrm{PhD}$ thesis. Hong Kong University of Science and Technology.

Cheung, R. W. M. \& Tang, W. H. (2000). Bayesian calibration of slope failure probability. In Slope Stability 2000, Proceedings of GEO-Denver 2000 (eds D. V. Griffiths, G. A. Fenton and T. R. Martin), pp. 72-85. Reston, VA: ASCE, Geotechnical Special Publication No. 101

Cheung, W. M., Shiu, Y. K. \& Pang, P. L. R. (2001). Assessment of global landslide risk posed by old man-made slopes in Hong Kong. Proceedings of the international conference on landslides: causes, impacts and countermeasures, Davos, pp. 497-505.

Christian, J. T., Ladd, C. C. \& Baecher, G. B. (1994). Reliability applied to slope stability analysis. J. Geotech. Engng, ASCE 120, No. 12, 2180-2207.

DeGroot, D. J. \& Baecher, G. B. (1993). Estimating autocovariance of in-situ soil properties. J. Geotech. Engng Div., ASCE 119, No. 1, 147-166.

El-Ramly, H., Morgenstern, N. R. \& Cruden, D.M. (2002). Probabilistic slope stability analysis for practice. Can. Geotech. J. 39, 665-683.

Einstein, H. H. (1997). Landslide risk: systematic approaches to assessment and management. Proceedings of the landslide risk workshop (eds Cruden and Fell), pp. 25-50. Honolulu, HI: IUGS Working Group on Landslides.

Fell, R. (1994). Landslide risk assessment and acceptable risk. Can. Geotech. J. 31, 261-272.

Fyfe, J. A., Shaw, R., Campbell, S. D. G., Lai, K. W. \& Kirk, P. A. (2000). The quaternary geology of Hong Kong. Hong Kong: Geotechnical Engineering Office.

Hollander, M. \& Proschan, F. (1979). Testing to determine the underlying distribution using randomly censored data. Biometrics 35, 393-401.

Juang, C. H., Rosowsky, D. V. \& Tang, W. H. (1999). Reliabilitybased method for assessing liquefaction potential of sandy soils. J. Geotech. Geoenviron. Engng, ASCE 125, No. 8, 684-689.

Juang, C. H., Chen, C. J., Rosowsky, D. V. \& Tang, W. H. (2001). CPT-based liquefaction analysis. Part 2: Reliability for design. Géotechnique 50, No. 5, 593-599.

Keaveny, J. M., Nadim, F. \& Lacasse, S. (1989). Autocorrelation functions for offshore geotechnical data. Proc. 5th Int. Conf. on Structural Safety and Reliability, San Francisco, 263-270.

Lacasse, S. \& Nadim, F. (1996). Uncertainties in characterising soil properties (Plenary). Proc. Uncertainty '96: Uncertainty in the Geologic Environment, from Theory to Practice, Madison (eds C. D. Shackelford, P. P Nelson and M. J. S. Roth) 1, pp. 49-75. ASCE, Geotechnical Special Publication No. 58.

Low, B. K. \& Tang, W. H. (1997). Efficient reliability evaluation using spreadsheet. J. Engng Mech., ASCE 123, No. 9, 749-752.

Li, K. S. \& Lumb, P. (1987). Probabilistic design of slopes. Can. Geotech. J. 24, 520-535. 
Morgenstern, N. R. (1997). Toward landslide risk assessment in practice. Proceedings of the landslide risk workshop (eds Cruden and Fell), pp. 15-23. Honolulu, HI: IUGS Working Group on Landslides.

Nelson, W. (1972). Theory and applications of hazard plotting for censored failure data. Technometrics 14, 945-966.

Ruxton, B. P. (1960). The geology of Hong Kong. Q. J. Geol. Soc. London 115, 233-260.

Sewell, R. J., Campbell, S. D. G., Fletcher, C. J. N., Lai, K. W. \& Kirk, P.A. (2000). The pre-quaternary geology of Hong Kong. Hong Kong: Geotechnical Engineering Office.

Soulie, M., Moutes, P. \& Silvestri, V. (1990). Modeling spatial variability of soil parameters. Can. Geotech. J. 27, 617-630.

Tang, W. H. (1984). Principle of probabilistic characterization of soil properties. Proceedings of the ASCE symposium on prob- abilistic characterization of soil properties: bridge between theory and practice, Atlanta, pp. 74-98.

Vanmarcke, E. H. (1977). Reliability of earth slopes. J. Geotech. Engng Div., ASCE 103, No. 11, 1247-1265.

Weibull, W. (1951). A statistical distribution function of wide applicability. J. Appl. Mech. 18, 293-297.

Wu, T. H., Tang, W. H. \& Einstein, H. H. (1996). Landslide hazard and risk assessment, Landslides Investigation and Mitigation, Special Report 247 (eds A. K. Turner and R. L. Schuster). Washington, DC: Transportation Research Board, National Research Council, pp.106-118.

Yu, Y. F. (2004). Correlations between rainfall, landslide frequency and slope information for registered man-made slopes, GEO Report 144. Hong Kong: Geotechnical Engineering Office. 